\title{
Design and Development of IoT enabled Multi Robot System for Search and Rescue Mission
}

\author{
Rajesh Singh, Rohit Samkaria, Anita Gehlot, Sushabhan Choudhary \\ University of Petroleum and Energy Studies, Dehradun \\ India \\ rsingh@ddn.upes.ac.in \\ rohit.samkaria93@gmail.com \\ anita@ddn.upes.ac.in \\ schoudhary@ddn.upes.ac.in
}

\begin{abstract}
It can be admitted that multi robot systems have better possibilities of success in accomplishing surveillance and rescue missions. In proposed system, a multi robot system based on swarm intelligence is developed which will help in surveillance with real time data uploading on cloud using IoT and perform rescue missions. The objective of this paper is to develop wireless intercommunication between multiple agents so that they perform the given task in synchronized manner and to develop a control strategy for robots using PID technique and further optimizing it using ant colony optimization (ACO) algorithm. The presented system consists of two robots with temperature sensing, fire sensing and hazardous gas sensing features and a hand held device which receives this information and handheld device is incorporated with the NodeMCU unit that upload the data on BLYN app. These robots also have capability of sending live videos using wireless camera. The paper also consists of development of hardware along with simulation results of the system.
\end{abstract}

Keywords: Multi-Agent, Swarm, PID, ACO, Surveillance, IoT, ZigBee

Received: 18 November 2017, Revised 22 December 2017, Accepted 10 January 2018

DOI: $10.6025 /$ ijwa/2018/10/2/51-63

(C) 2018 DLINE. All Rights Reserved

\section{Introduction}

For ease of human work now day's robots are being utilized for various applications because in number of cases it is not feasible for humans to interact with the landmines, nuclear reactor, mines etc. A single robot designed to perform multiple function may achieve predefined task but at the same time failures of this robot result to be more dangerous for the mission [1]. Ying TAN et. al has given the example of ant colonies, school of fishes; bird crowd etc. and concluded that in this nature various species from a long time ago taking the advantage of swarm power to survive from cruel nature instead of wisdom of individuals and [2]. Swarm robotics has great application in search and rescue missions. Search and rescue missions can be dangerous for humans because most of the time they remain unaware of the situation, they don't know what is happening there, how many enemies they have in the affected area or what are the environmental conditions like fire, any hazardous gases etc. So instead of sending human we can send multiple robots for gathering information. Markus Bernard et. al has given a system based on aerial robot for search and rescue missions which are autonomous [5]. In ant colonies, several groups are made according to the role given. Ants communicate with each other using pheromone, sound, and touch [3]. Like bee colonies, in swarm, the agents complete the complex tasks by developing co-ordination between agents. In swarm, robots have to stick together in order to achieve the success, so there should be a communication mechanism or technique for this. Patrick Benavidez et. Al for different application

International Journal of Web Applications Volume 10 Number 2 June 2018 
in swarm communication and navigation provide a feasible solution. He used XBee-PRO radio modems for inter-swarm communication [4]. In this system, we are using Zigbee modems for inter communication between robots. It operates on $2.4 \mathrm{GHz}$ band. It can operate in half duplex and duplex mode. In search and rescue missions, it is necessary to have control over the robots, there should be a synchronization between the motors otherwise it will take robot away from the target. Manoj Kushwah et. al says that the PID controller is one of the most commonly used compensating controller for nonlinear systems [6]. Ritu Soni et. al says that PID controllers can commonly utilized for motor control application because of their simplicity. PID controllers use mathematical models for control applications and utilizes in reducing the steady state error and to improve the dynamic response [7]. But to find proper PID controller for particular application is tedious task [8]. A lot of methods have been proposed for tuning PID controller with respect to time. Ziegler-Nichols tuning method is mostly used because most of the time it is difficult to find best control parameters for PID controller [9]. ]. So in recent years, many techniques for optimizing the control parameters for PID controller have been developed such as neural network [10], fuzzy logic, neural-fuzzy logic [11] etc. Other methods for tuning PID inspired form nature such as genetic algorithm (GA) [12], particle swarm optimization [13], and ant colony optimization [14] have developed in recent years. Mishra A. K et al says by using artificial bee colony optimization technique, we can design and tune parameter of PID controller to get better dynamic and static performance [15]. The paper described a path-finding robot using ultrasonic range finder sensor. This robot is able to learn the maze and corresponding finds the path.PID (Proportional Integral Derivative) controllers are best utilized to find out the controller parameter and most preferably used in all industry around the globe due to their robustness, applicability to a variety of processes and due to their simplicity. PID controller used the mechanism of Control Loop Feedback which continuously calculates the Error value between the desired value and a measured process variable.

$$
u(t)=K_{p} e(t)+K_{i_{0}}^{t} e(t) d t+k_{d} \frac{d e(t)}{d t}
$$

Where the $K p, K i$, and $K d$ are all non-negative and are various coefficients for the proportional, integral and derivative where $p$ represent the error value and the control output depend upon the error input if the error input is large and positive the corresponds control output also be large and i denotes for the past values of the error and $d$ accounts for the future value of the error. The equation below gives the transfer function of the PID controller:-

$$
G(s)=K_{p}+K_{i} / s+K_{d} s
$$

Where $K p$ is the Proportional gain, $K i$ is the Integral Gain and $K d$ is the Derivative Gain.

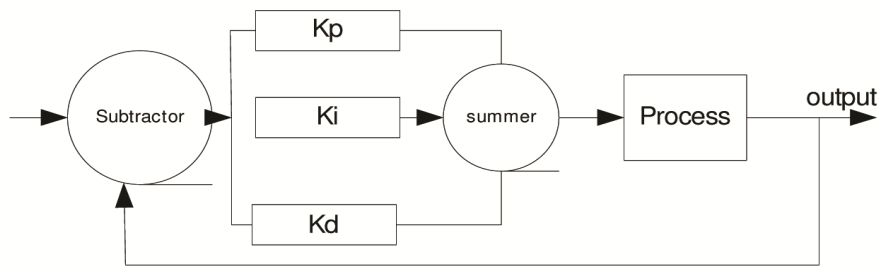

Figure 1. Block diagram of the PID controller

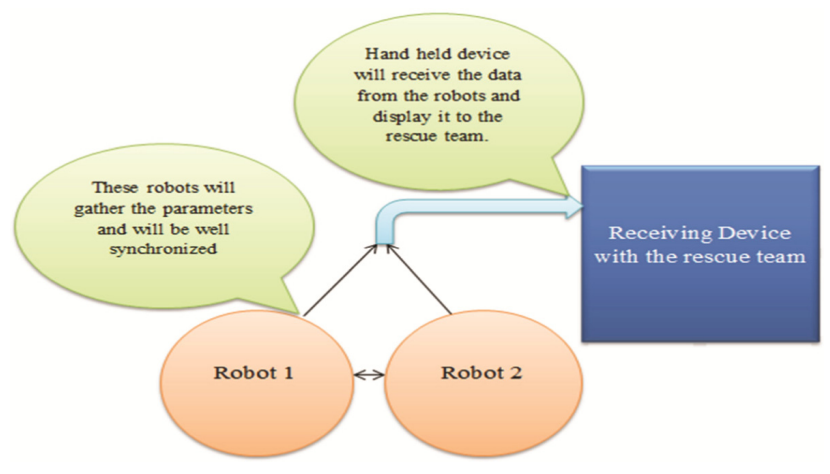

Figure 2. Block of the proposed system 


\section{Hardware Development}

\subsection{Proposed System}

The signal flow block diagram of the proposed system is shown in the figure 2 . The proposed system consists of two robots on which a fire sensor, temperature sensor, gas sensor and a Wi_Fi camera is attached. A magnetic compass will be attached to each robot for following a particular direction. An ultrasonic sensor is used for maintaining a particular distance between the robots. So our proposed system will help rescue team in gathering information of the parameters related to that area instead of facing the situation directly.

\subsection{PID Controller}

PID controller is required to find out the best controller parameters like $K_{p}, K_{i}, K_{d}$. PID controllers are widely used in industries because of their simplicity in structure, robustness and applicability to a variety of processes. PID controller is tuned to obtain desired closed loop performance, based on the dynamic model of system and then implement the results using suitable platform to program the valid values. PID is a feedback based controller which gets the error value and calculates the output based on the characteristics of the error [17]. The transfer function for PID controller is given by equation as below:

Where

$K_{p}$ - Proportional gain

$K_{i}$ - Integral gain

$K_{d}$-Derivative gain

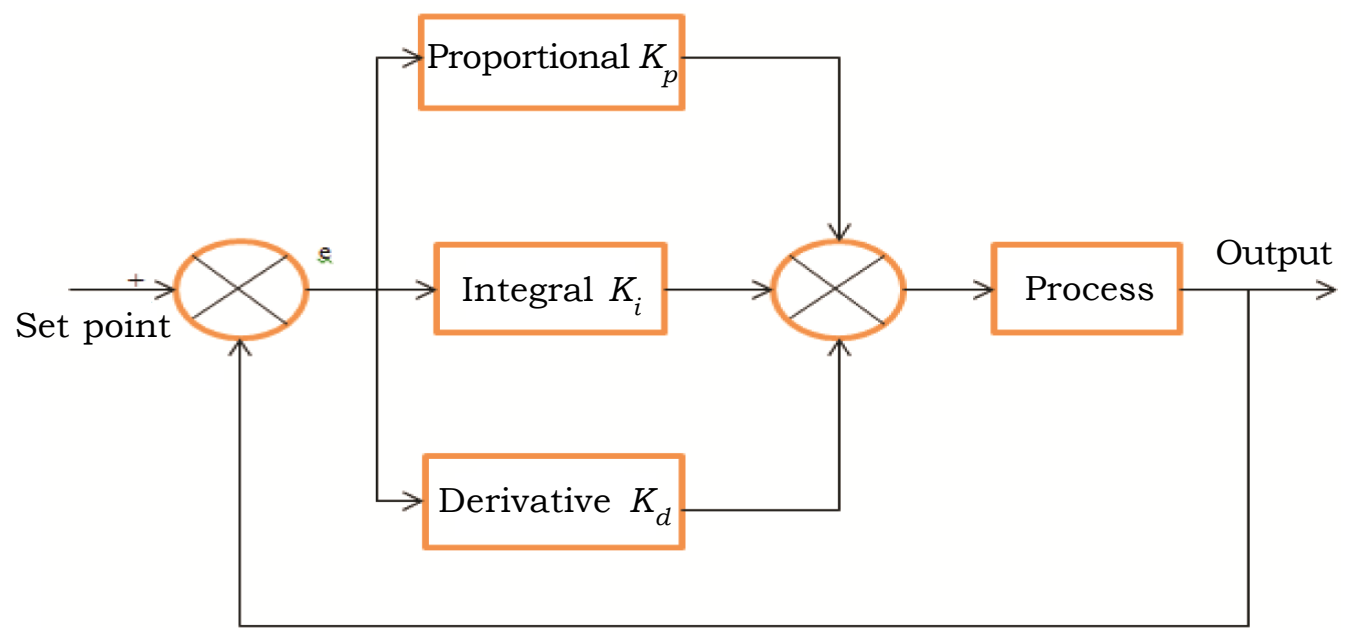

Figure 3. Block diagram of the PID controller

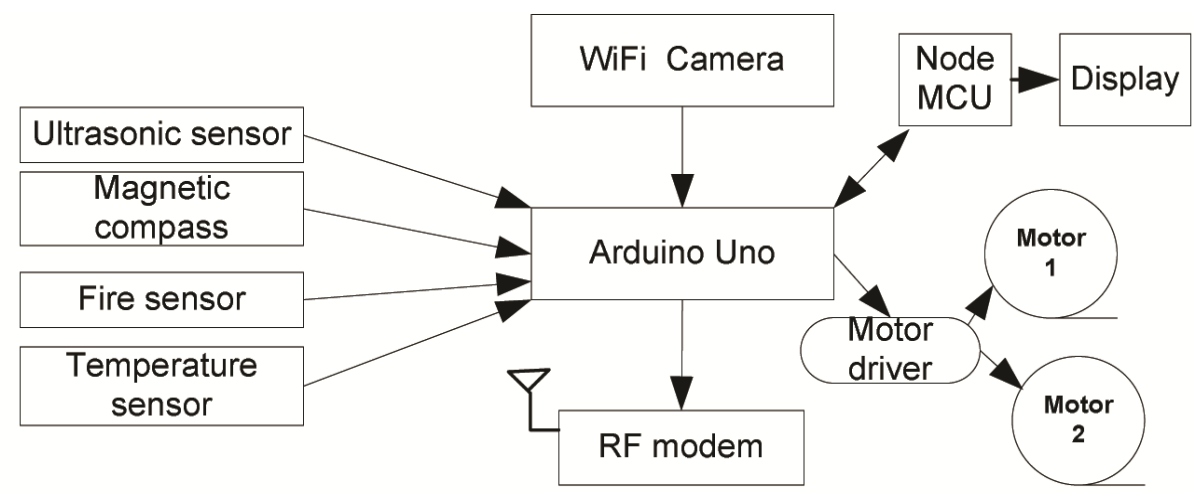

Figure 4. Block diagram of the individual robot 


\subsection{Robot Section}

The given below Figure3 shows the signal flow block diagram of the robot. When robots are sent into the affected area, they follow a particular direction by using magnetic compass. While moving, gas sensor, temperature sensor and fire sensor will collect the information of presence of any hazardous gas, temperature of that area and presence of fire respectively and this information will be wirelessly sent by RF modem to a receiving device which is kept with the rescue team. Ultrasonic sensor is used to keep both the robots in fitness distance (it is the distance which a robot eager to keep with another robot in swarm [16]). Wi-Fi camera is used to get the live video of the area.

It is required to have synchronization between the motors of the robot, the motors of robot should move with same and desired speed. So for this, we have used PID technique to achieve desired speed of motors.

\subsection{Hand Held Device}

Figure 5 shows the signal flow block diagram of the receiving section of system. This part of the system will be kept with the rescue team. Here RF modem will receive the information from the robots and the microcontroller will show this information with the help of display unit.
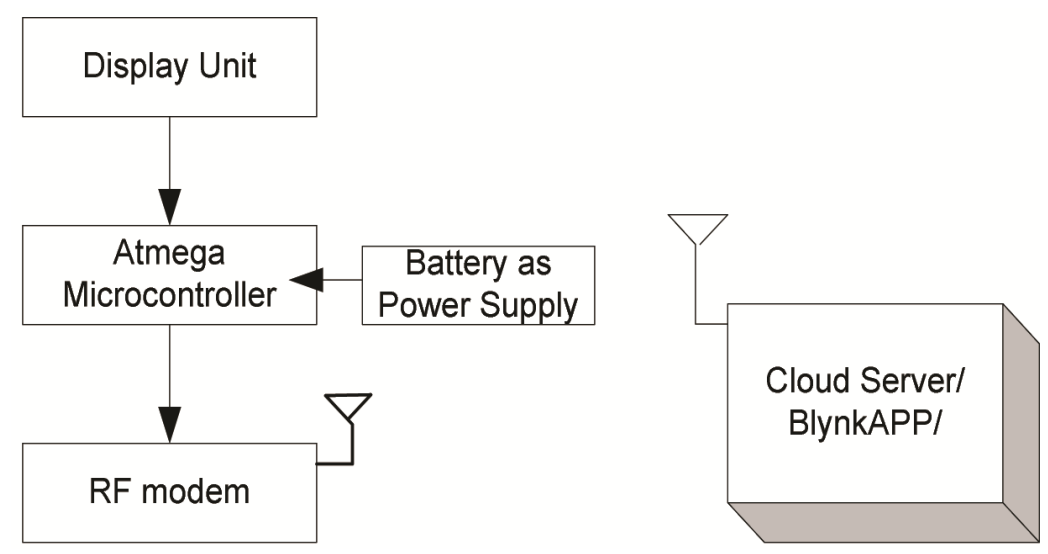

Figure 5. Block diagram of the receiving section and cloud server (local and with Blynk APP)

\subsection{Retrieving Data from Base Station and Connecting to the IoT Platform}

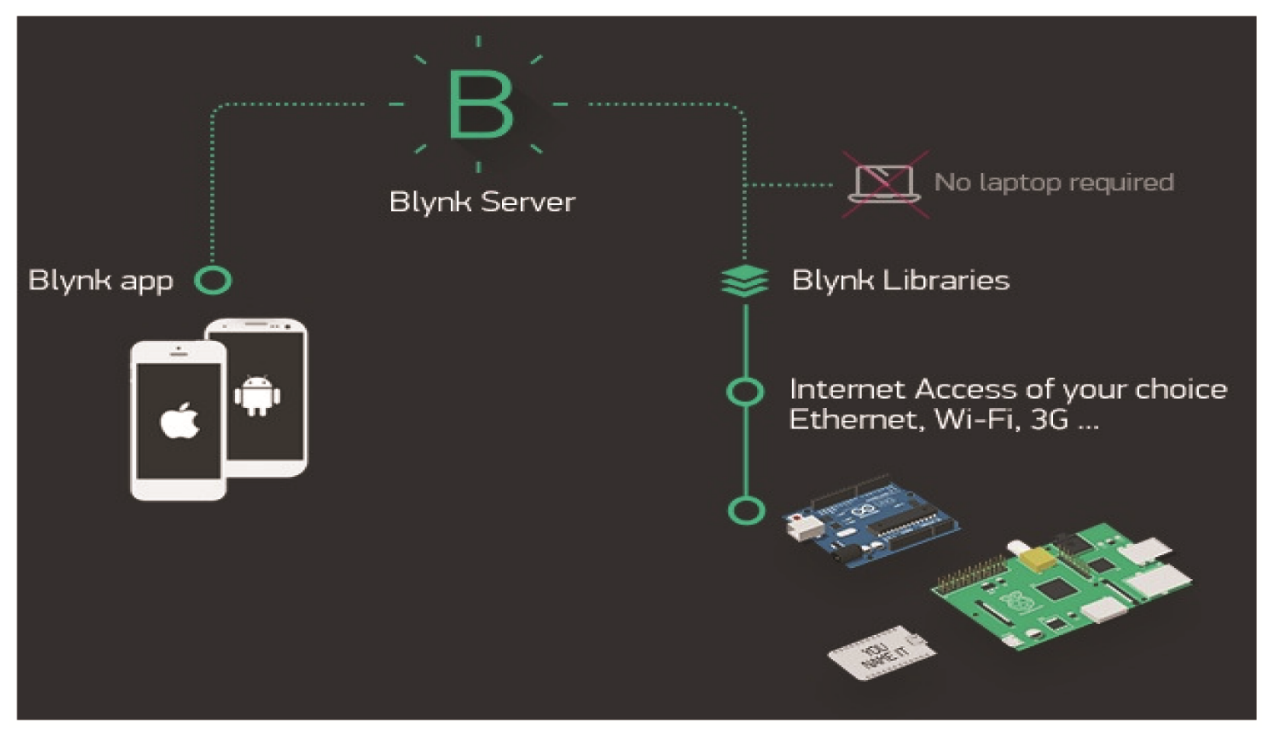

Figure 6. Blynk Architecture 
Blynk is an open source platform trhat is developed to to work with Arduino, NodeMCU. Blynk works over the internet. So in order to communicate with Blynk the hardware need to be incorporated with internet connection. The blynk libraries are uploaded in the firmwafre that communicate with the hardware.

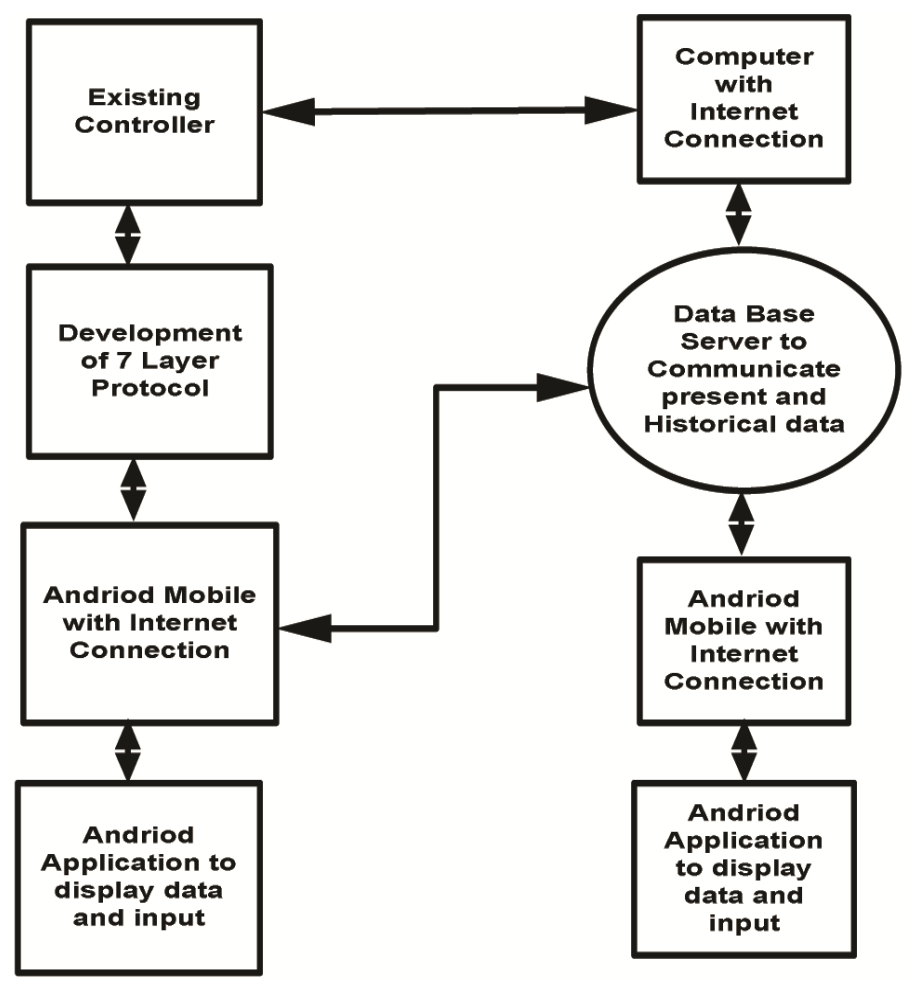

Figure 6. Basic Architecture of IoT (Internet of Things)

When data is received at the hand held device then it fed to the NodeMCU to communicate with the http protocol.

Figure 4 showing up the basic architecture of IoT development protocol.

Before sending the data to the cloud we need to configure out BLYNK platform in order to manage the data receiving from the base station. BLYNK uses a hierarchical structure to group and manage the data. The steps shown in the figure are very fast and we can do them only once. It represents the physical device that we are using to send and receive the data. The configuration steps are completed then we are connecting our controller device to BLYNK and starts sending data over the aap.

The NodeMCU WiFi control configuration:

wifi for overall WiFi configuration

wifi.sta for station mode functions

wifi.ap for wireless access point (WAP or simply AP) functions

wifi.ap.dhcp for DHCP server control

wifi.eventmon for wifi event monitor

\section{Software Development}

\subsection{Software Algorithm required for PID Controller tuning with ACO}

1. First of all need to initialize the parameters i.e. number of ants, number of iteration, strength of pheromone, decay rate. 
2. Then initialize the values of $K P, K I$ and $K D$ for PID controller

3. Probability is calculated for each ant transition.

4. Incrementally builds a solution and local pheromone update.

5 Update the best solution.

6. Update a global pheromone.

7. The steps from 3 to 6 repeated continuously until the maximum iteration reached.

8. Get the optimized values of $K p, K i$ and $K d$.

\subsection{Implementation of PID and ACO}

First PID is used to get control parameters, then ACO is implemented to optimize the value of $K p, K i, K d$ to get the best value.

The value of control parameter of PID controller after applying PID + ACO is

$=2.75462732042938$

$=0.608721640263219$

$=0.710908594996224$

The simulation part is shown below for PID and ACO technique.

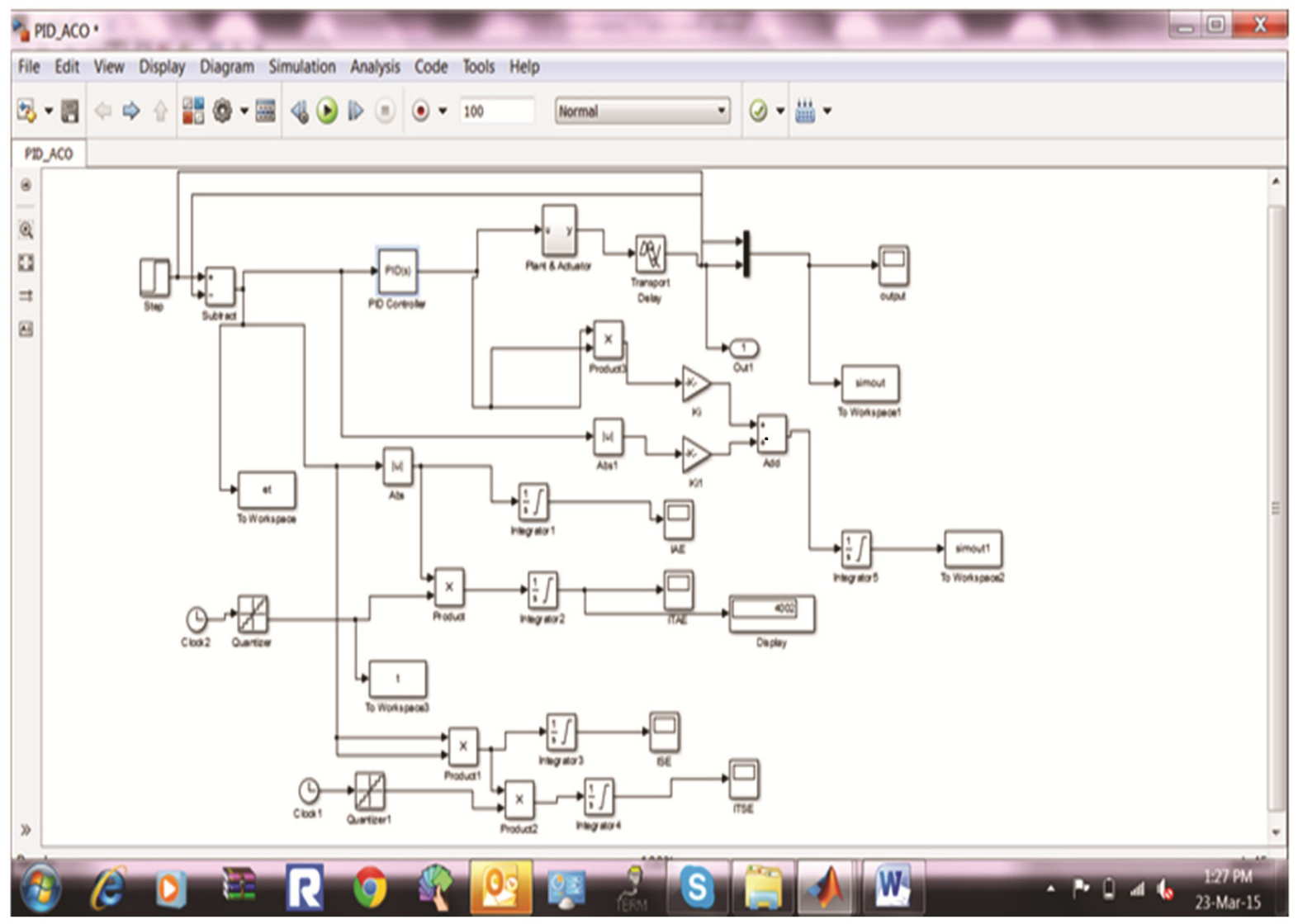

Figure 7. Mathematical model of PID+ACO 


\subsection{Components Detail}

\begin{tabular}{|c|c|c|c|}
\hline S.No. & Device/Module & Make/ Model no. & Specifications and working \\
\hline 1. & LCD & Sunrom model no. 3013 & $\begin{array}{l}\text { This is } 16 \times 2 \text { LCD. In this project, it is used to display the status of } \\
\text { presence of fire, presence of any hazardous gas and temperature } \\
\text { of the area which the receiving device getting from robots. }\end{array}$ \\
\hline 2. & Atmega8 \& 16 & Atmel & $\begin{array}{l}\text { It is a low-power CMOS 8-bit microcontroller based on the AVR } \\
\text { RISC architecture which operates on } 5 \mathrm{~V} \text {. Atmega16 is used for } \\
\text { swarm robots and Atmega8 is used for receiving device. }\end{array}$ \\
\hline 3. & NodeMcu & NodeMCU & $\begin{array}{l}\text { NodeMCU is a open source platform that includes firmware } \\
\text { DEVKIT } 1.0 \text { which run over ESP } 8266 \text { Wi-Fi SOC. }\end{array}$ \\
\hline 4. & Zigbee modem & $\begin{array}{l}\text { Sunrom model } \\
\text { no.1197[11] }\end{array}$ & $\begin{array}{l}\text { It is wireless serial communication RF modules which operates in } \\
2.4 \mathrm{Ghz} \text { free ISM band. It can operate in half duplex and duplex } \\
\text { mode. It operates in UART mode with microcontroller. }\end{array}$ \\
\hline 5. & Gas sensor & $\begin{array}{l}\text { Sunrom model } \\
\text { no. } 1220 \mathrm{~B}\end{array}$ & $\begin{array}{l}\text { This sensor is used to detect the presence of LPG, iso-butane, } \\
\text { propane, LNG combustible gases. }\end{array}$ \\
\hline 6. & $\begin{array}{l}\text { Temperature } \\
\text { sensor (LM35) }\end{array}$ & $\begin{array}{l}\text { Sunrom model } \\
\text { no. } 3001\end{array}$ & $\begin{array}{l}\text { Its output is linearly proportional to the Celsius (Centigrade) i. e. } \\
\text { it directly gives output in the Celsius. It has scale factor of }+10.0 \\
\mathrm{mV} / \text { !. }\end{array}$ \\
\hline 7. & Ultrasonic sensor & $\begin{array}{l}\text { Sunrom model } \\
\text { no. } 3719\end{array}$ & $\begin{array}{l}\text { Ultrasonic sensor is used to measure the distance between two } \\
\text { objects. Sensor gives pwm output which can be easily read. }\end{array}$ \\
\hline 8. & $\begin{array}{l}\text { Fire detector } \\
\text { sensor }\end{array}$ & Robosoft system & $\begin{array}{l}\text { Fire sensor is used to detect the presence of fire. This sensor uses } \\
\text { IR sensor and comparator to detect fire up to the range of } 1 \text { meter. }\end{array}$ \\
\hline 9. & Magnetic compass & $\begin{array}{l}\text { Sunrom model } \\
\text { no.3932 }\end{array}$ & $\begin{array}{l}\text { This product is } 3 \text {-Axis Digital Compass IC. It gives direction data } \\
\text { with respect to earth magnetic field. It operates on I2C mode. }\end{array}$ \\
\hline 10. & L293d & $\begin{array}{l}\text { ST } \\
\text { Microelectronics }\end{array}$ & $\begin{array}{l}\text { L293d is high voltage and high current four channel driver IC } \\
\text { which is used to drive dc motor. }\end{array}$ \\
\hline 11. & DC motors & $\begin{array}{l}\text { Sunrom model } \\
\text { no. } 3213\end{array}$ & It is high efficiency, low cost geared motor. Operates on $12 \mathrm{~V}$. \\
\hline 12. & Power supply & & $\begin{array}{l}\text { For robots and receiving device, all the devices operates on } 5 \mathrm{~V} \\
\text { accept dc motors which operate on } 9 \mathrm{~V} \text {, so } 9 \mathrm{~V} \text { battery is used } \\
\text { with } 7805 \text { regulator to achieve } 5 \mathrm{~V} \text { and LED is connected as } \\
\text { indicator. }\end{array}$ \\
\hline
\end{tabular}

Table 1. Components details used in the system

\section{Circuit Simulation}

The given below figure7 shows the circuit diagram of swarm robots. Each robot consists of a controlling device called microcontroller. We have used Atmega16 microcontroller for swarm bots. For gathering information, we have used fire sensor, 
temperature sensor and gas sensor. Fire sensor is of digital nature and output pin of sensor is attached to pin PB0 of PORTB of microcontroller. Temperature sensor is of analog nature and output pin of sensor is connected to pin PA1 of PORTA of microcontroller. Gas sensor is also of analog nature and output pin of sensor is connected to pin PA0 of PORTA of microcontroller. Ultrasonic sensor is connected to pin PD5 of PORTD of microcontroller. A digital compass is of I2C nature so we require two pin of microcontroller- SCL and SDA which are pin PC0 and PC respectively of PORTC. A crystal oscillator is used of $14.7456 \mathrm{Mhz}$ frequency. Crystal oscillator is a two leg device and it is connected to pin no. 12 and 13 of microcontroller. A RF Modem is connected for wireless communication between robots and hand held device. It is four pin device- one vcc, one ground and rest two are Rx and Tx. These Rx and Tx pins are connected to pin no. 14 and 15 of microcontroller. For the movement of robot, two motors are used. Motors are operated with the help of a motor driver IC called L293d. L293d is 16 pin IC- pin no. 1, 9, 16 are connected to $5 \mathrm{~V}$, pin no. 8 is connected to $12 \mathrm{~V}$, pin no. $4,5,12,13$ are connected to ground, pin no. $2,7,10,15$ are connected to pin PC4, PC5, PC6, PC7 of Atmega16 respectively, pin no. 3, 6 are connected to motor 1 and pin no. 11, 14 are connected to motor 2. A wireless camera is mounted on the robot for the live videos. This wireless camera sends the videos to a laptop.

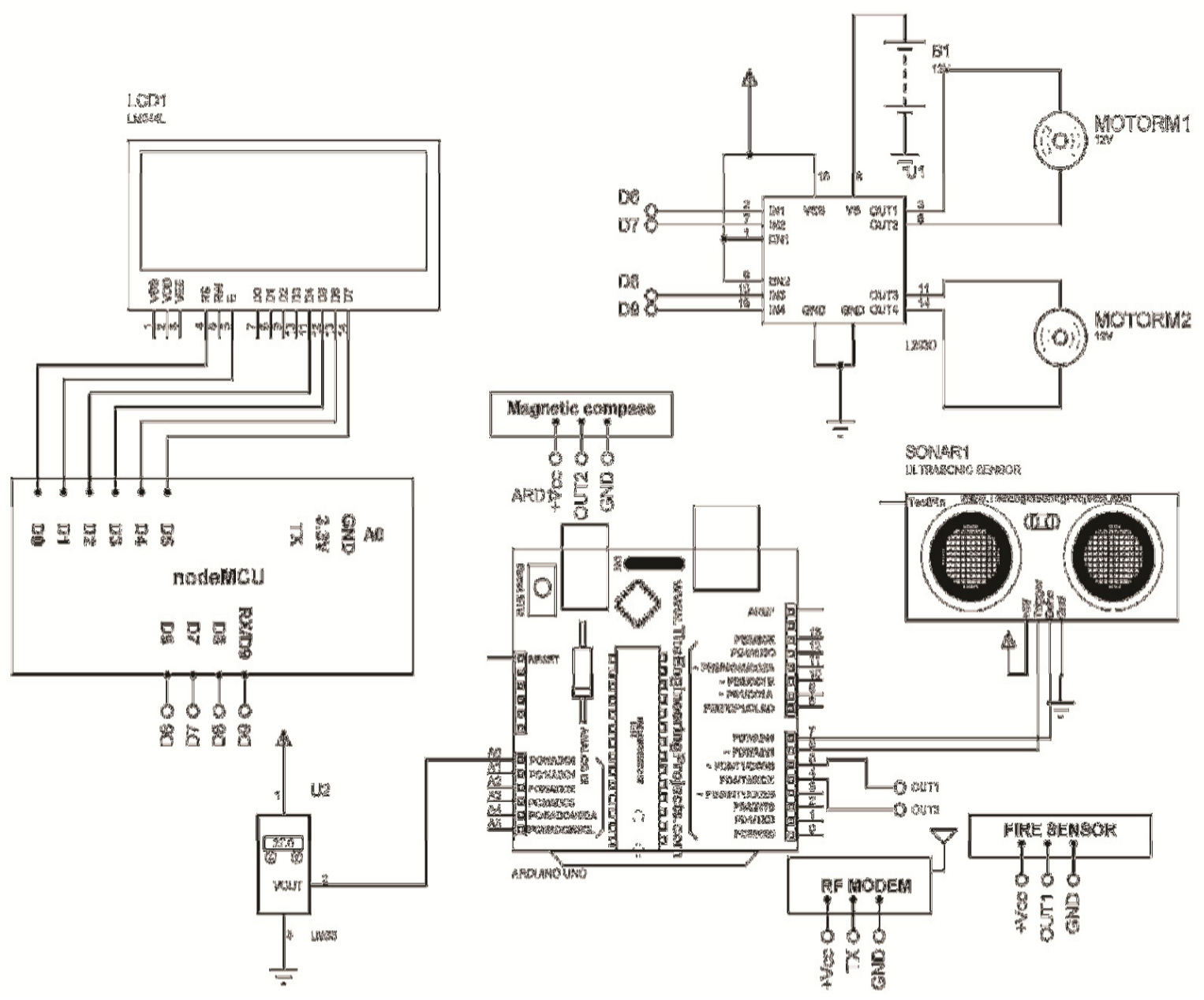

Figure 9. Circuit diagram of the robot section

The given below figure shows the circuit diagram of hand held device which will receive the data from the swarm robots. For this section, we have used Atmega8 microcontroller. A 16*2 LCD is used here for displaying the information sent by robots. A 16*2 LCD has 16 pins. For connecting LCD with Atmega8, connect pin no. 1,3,16 of LCD with ground, pin no. 2, 15 with 5V, pin no. 4, 5, 6 of LCD with pin no. 12, 11, 13 of Atmega8 and connect the data pin (D4-D7) of LCD to the pin PC0-PC3 of PORTC of Atmega8 respectively. For wireless communication, connect RF modem with Atmega8. RF Modem is four pin device- one vcc, one ground and rest two are Rx and Tx. These Rx and Tx pins are connected to pin no. 2 and 3 of Atmega8. A crystal oscillator is also connected to pin no. 9 and 10 of Atmega8.

58 International Journal of Web Applications Volume 10 Number 2 June 2018



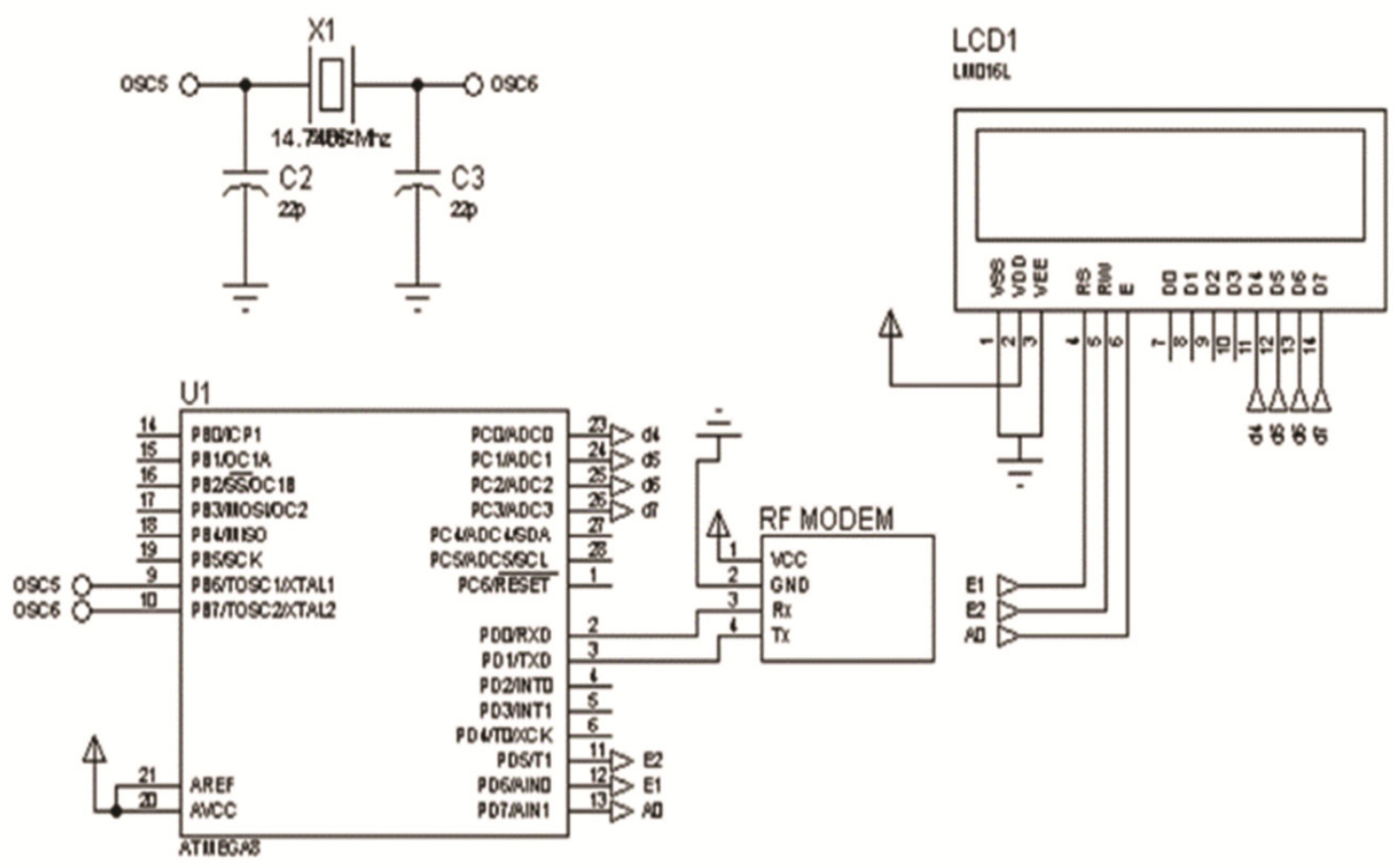

Figure 10. Circuit diagram of the receiver section

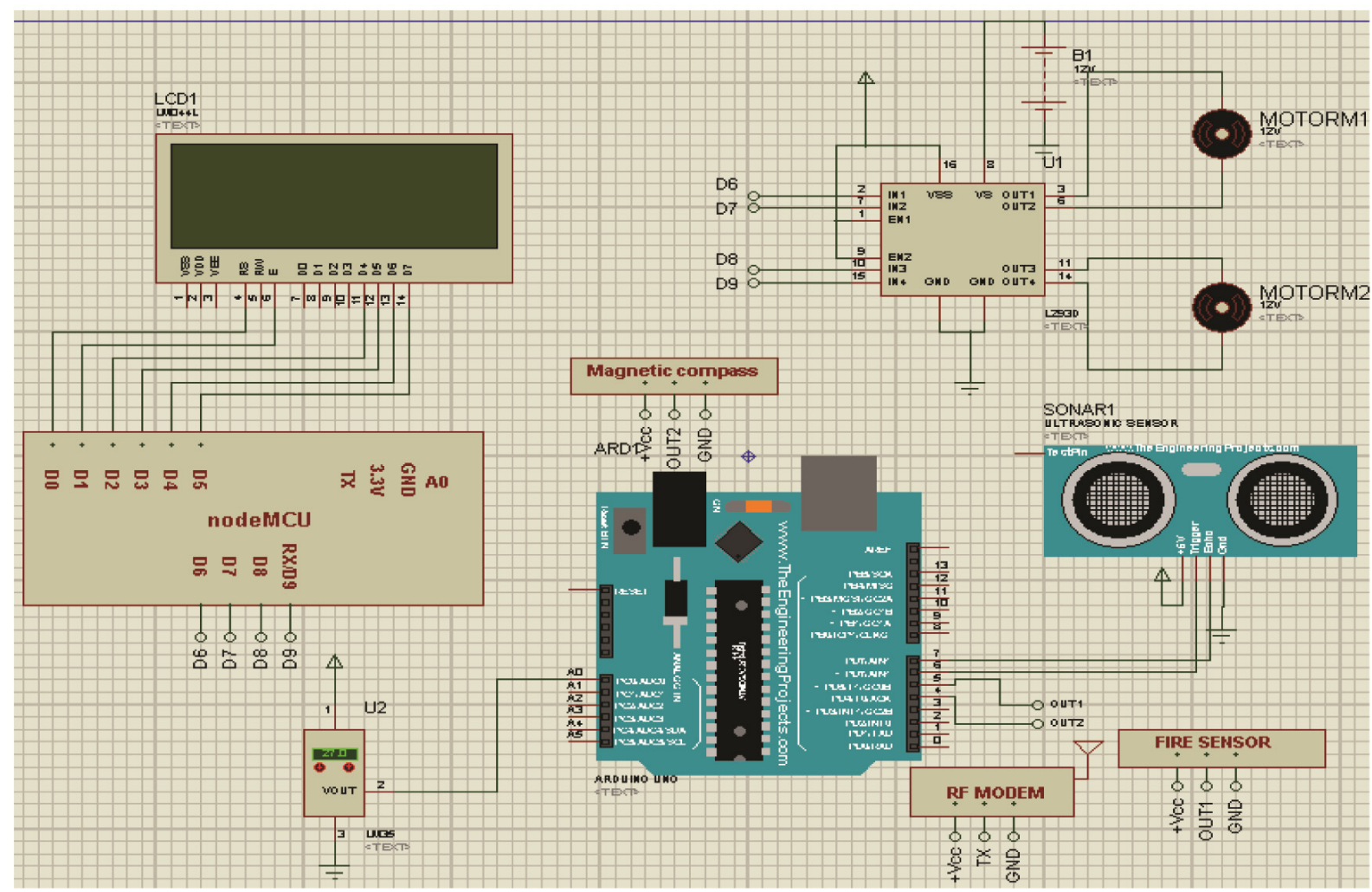

Figure 11. Proteus simulation of the robot section 


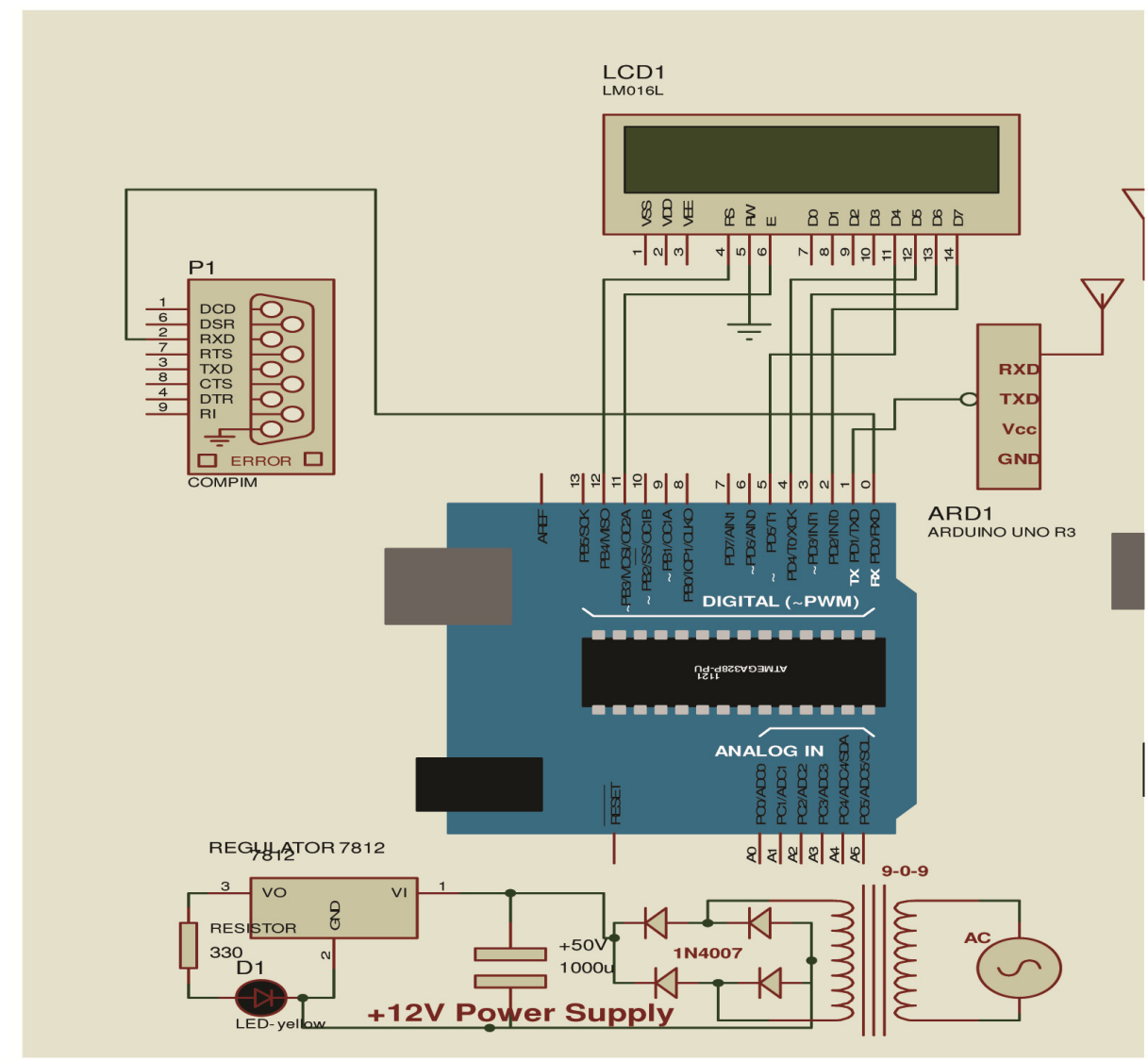

Figure 12. Proteus simulation of the receiver section

\section{Experimental Setup}

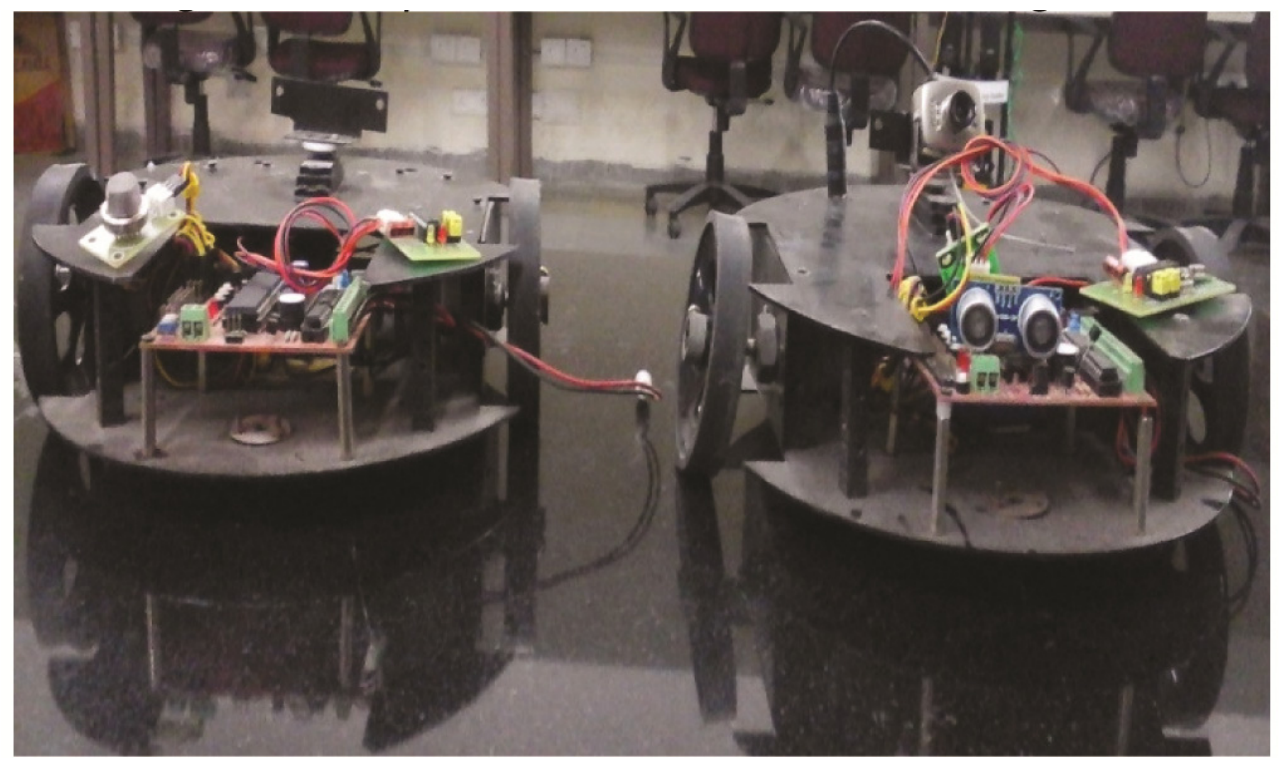

Figure 13. Developed robot section 


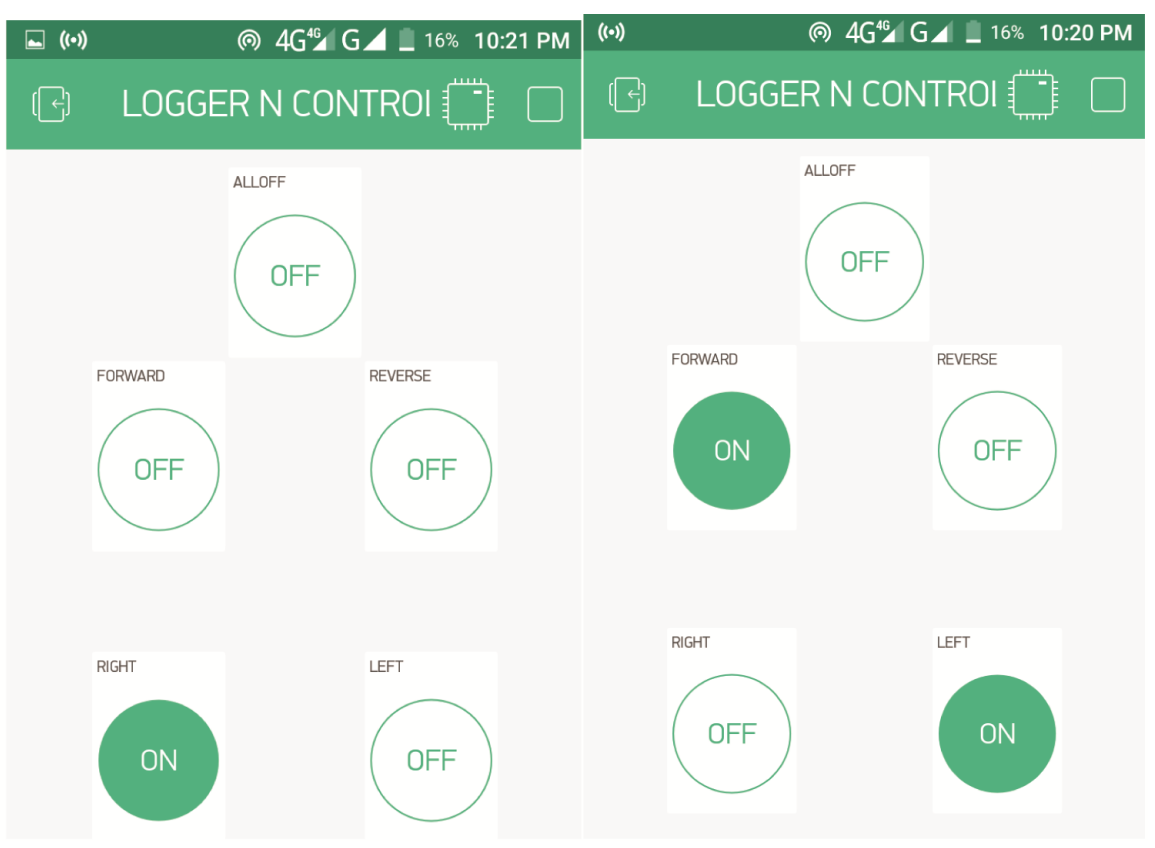

Figure 14. Local server at IP 192.168.43.4 based mobile robot control

The experimental setup can be divided into two parts- one is robot section and another is hand held device which is a receiving section. Figure 13 shows robot section which consists of two robots. These robots consist of fire sensor, gas sensor, temperature sensor, magnetic compass, ultrasonic sensor and Zigbee modem.

Figure 14 show the robot control platform develpoed over the Blynk aap these radion button trasit the digitally value to the internet incorporated hardware where various conditional algorithm is developed to take action correspondes to the digiotal value received.

\section{Result and Discussion}

In this paper, an effective solution is provided to help in surveillance and rescue missions. It is observed that the robots are capable of sensing temperature, status of fire and presence of hazardous gases if any presents. System is also sending the information to the hand held device. The handheld device incorporated with NodeMCU upload the data to the Blynk app. Robot can be controlled through Blynk app that is communicated with the hardware. The system is designed using various hardware and software techniques which are ecofriendly and economical. It is also observed that the PID and ACO technique used in this paper is capable of synchronizing the speed of motors. The system is useful in gathering information of a place which has gone through any attack or terrorism activity and this information will help the army or rescue team in making their strategies.

\section{References}

[1] Venayagamoorthy, Ganesh, K., Lisa, L. Grant, Sheetal Doctor. (2009). "Collective robotic search using hybrid techniques: Fuzzy logic and swarm intelligence inspired by nature." Engineering Applications of Artificial Intelligence 22.3: 431-441.

[2] Tan, Ying., Zhong-yang Zheng. (2013). "Research advance in swarm robotics." Defence Technology 9.1: 18-39.

[3] Jackson, Duncan, E., Francis LW Ratnieks. (2006). “Communication in ants.” Current biology 16.15 (2006): R570-R574.

[4] Benavidez, Patrick. (2008). "Multi-domain robotic swarm communication system.” System of Systems Engineering, 2008. SoSE'08. IEEE International Conference on. IEEE.

[5] Yuan, Jiann-Shiun. (2017). "Ultra-Low-Power Design and Hardware Security Using Emerging Technologies for Internet of Things." Electronics 6.3: 67. 
[6] Wang, Qichen., Phillips, Chris. (2014). Cooperative Path-Planning for Multi-Vehicle Systems. Electronics 3 (4) 636-660.

[7] Bernard, Markus. (2011). Autonomous transportation and deployment with aerial robots for search and rescue missions. Journal of Field Robotics 28.6: 914-931.

[8] Kushwah, Manoj., Patra, Ashis. (2014). Tuning PID Controller for Speed Control of DC Motor Using Soft Computing Techniques-A Review, Advance in Electronic and Electric Engineering, 4 (2) 141-148.

[9] Soni, Ritu. (2013). Simulation of Optimal Speed Control for a DC Motor Using Conventional PID Controller and Fuzzy Logic Controller. International Journal of Information and Computation Technology 3 (3) 181-188.

[10] Oonsivilai, A., Pao-La-Or, P. (2008). Application of adaptive tabu search for optimum PID controller tuning AVR system, WSEAS Transactions on Power Systems, 3 (6) 495-506.

[11] Chiha, Ibtissem., Liouane, Noureddine., Borne, Pierre. (2012). Tuning PID controller using multiobjective ant colony optimization. Applied Computational Intelligence and Soft Computing 11.

[12] Cao, C., Guo, X., Liu, Y. (2007). Research on ant colony neural network PID controller and application, In: Proceedings of the 8th ACIS International Conference on Software Engineering, Artificial Intelligence, Networking, and Parallel/Distributed Computing (SNPD '07)253-258.

[13] Seng, T. L., Khalid, M. B., Yusof, R. (1999). Tuning of a neurofuzzy controller by genetic algorithm, IEEE Transactions on Systems, Man, and Cybernetics Part B, 29 (2) 226-236.

[14] Wang, P., Kwok, D. P. (1994). Optimal design of PID process controllers based on genetic algorithms, Control Engineering Practice, 2(4) 641-648.

[15] Mitsukura, Y., Yamamoto, T., Kaneda, M. (1999). A design of self-turning PID controllers using a genetic algorithm, In Proceedings of the American Control Conference, p. 1361-1365, San Diego, Calif, USA.

[16] Selvan, S. E., Subramanian, S., Solomon, S. T. (2003). Novel technique for PID tuning by particle swarm optimization, In Proceedings of the 7th Annual Swarm Users/Researchers Conference (SwarmFest '03) 2003.

[17] Hsiao, Y. T., Chuang, C. L., Chien, C. C. (2004). Ant colony optimization for designing of PID controllers, In: Proceedings of the IEEE International Symposium on Computer Aided Control Systems Design, Taipei, Taiwan.

[18] Mishra, A. K., Tiwari, V. K., Kumar, R., Verma, T. (2013). Speed control of de motor using artificial bee colony optimization technique, Control , Automation, Robotics and Embedded Systems (CARE), 2013 International Conference on 16-18 Dec. 2013, IEEE, 10.1109/CARE.2013.6733772.

[19], Tamotsu, Kamigaki( 2017). Object Oriented RFID with IoT: A Design Concept of Information Systems in Manufacturing. Electronics 6 (1) 14.

[20] WeiXing, Feng. (2006.) Novel algorithms for coordination of underwater swarm robotics. Mechatronics and Automation, Proceedings of the 2006 IEEE International Conference on.

[21] Liao, Yangzhe. (2016)Analysis of in-to-out wireless body area network systems: towards QoS-aware health internet of things applications. Electronics 5 (3) 38.

[22] Sultaniya, Shashank., Gupta, Rajeev. (2014).Design of PID Controller using PSO Algorithm for CSTR System, International Journal of Electronic and Electrical Engineering, 7(9)

[23] Tjiharjadi, Semuil, Setiawan, Erwin. (2016). Design and Implementation of a Path Finding Robot Using Flood Fill Algorithm. International Journal of Mechanical Engineering and Robotics Research, 5 (3) (July).

[24] Behmanesh, Mohammad., Hong, Tang Sai., Saufi, Muhamad Kassim, Mohd., Azim, Arsalan., Dashtizadeh, Zahra. (2016). A Brief Survey on Agricultural Robots. International Journal of Mechanical Engineering and Robotics Research, 6 (3) (July).

62 International Journal of Web Applications Volume 10 Number 2 June 2018 


\section{Author Biographies}

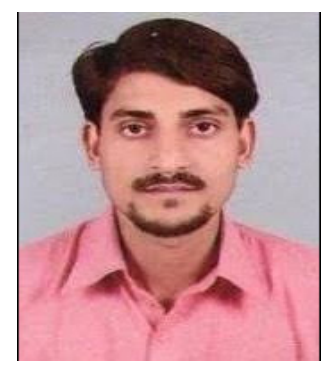

Dr. Rajesh Singh is currently associated with University of Petroleum and Energy Studies, Dehradun as Associate Professor and with additional responsibility as Head Institute of Robotics Technology (R\&D). He has been awarded a gold medal in M.Tech and honors in his B.Tech. His area of expertise includes embedded systems, robotics and wireless sensor networks. He has organized and conducted a number of workshops, summer internships and expert lectures for students as well as faculty. He has twelve patents and published around hundred research papers in referred journals/conferences. Under his mentorship students have participated in national/ international competitions including Texas competition in Delhi and Laureate award of excellence in robotics engineering in Spain. Twice in last four years he has been awarded with certificate of appreciation from University of Petroleum and Energy Studies for exemplary work. He got Certificate of appreciation for mentoring the projects submitted to Texas Instruments Innovation challenge India design contest, from Texas Instruments, in 2015. He has been honored with young investigator award at the International Conference on Science and Information in 2012. He has published books on "Embedded System based on Atmega Microcontroller" with NAROSA publishing house, "Arduino based Embedded System" with CRC press. He is editor to a special issue published by AISC book series, Springer with title "Intelligent Communication, Control and Devices 2016 \& 2017'.

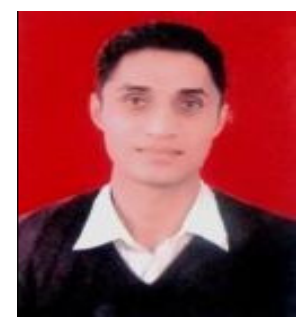

Mr. Rohit Samkaria is currently associated with University of Petroleum and Energy Studies, Dehradun. He received his B.Tech. degree in Electronics and Communication Engineering from Himachal Pradesh University, Shimla, India and M.Tech. degree in Electronics and Communication Engineering from Dr. A.P.J. Abdul kalam Technical University, Lucknow, India. His current Research includes Embedded System, Instrumentation Sensor, WSN.

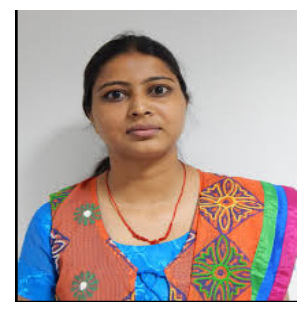

Ms. Anita Gehlot has more than 10 years of teaching experience in embedded systems and wireless sensor networks. She has 10 patents in her account. She has published more than fifty research papers in refereed journals and conferences. She has organized a number of workshops, summer internships and expert lectures for students. She has been awarded with certificate of appreciation from University of Petroleum and Energy Studies for exemplary work. She has published a book on "Embedded System based on Atmega Microcontroller" with NAROSA publication house, "Arduino based Embedded System" with CRC press. He is editor to a special issue published by AISC book series, Springer with title "Intelligent Communication, Control and Devices 2017.

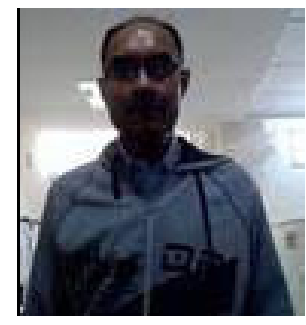

Dr. S. Choudhury is Head of the Department of Electronics, Instrumentation, and Control in the University of Petroleum and Energy Studies. He has teaching experience of 26 years and he has completed his Ph.D. from the University of Petroleum and Energy Studies, M.Tech (Gold Medalist) from Tezpur Central University, India and received his B.E. degree from NIT, Silchar University, India. He has published more than 70 papers in various national/international conferences/journals. He has filed 10 patents. His area of interest is Zigbee-based wireless networks. He has been selected as the outstanding scientist of the twenty-first century by the Cambridge Biographical Centre, UK. He has also been selected in the who's who of the world in science by Marquis Who's Who, USA. 